\title{
Lung and respiratory muscle function in limb girdle muscular dystrophy
}

\author{
J-P Stübgen, GJ Ras, CM Schultz, G Crowther
}

\begin{abstract}
Background - Pulmonary involvement is frequently observed in patients with limb girdle muscular dystrophy and occurs early in the disease. The aim of this study was to establish the prevalence of pulmonary dysfunction; the type of dysfunction; and any correlation between patient age, disease duration, or limb weakness and lung or respiratory muscle dysfunction.

Methods - Twenty patients with strictly delineated limb girdle muscular dystrophy and 20 healthy controls were evaluated. Full inspiration chest radiographs were obtained. Standard lung and respiratory muscle function tests were performed and the data were statistically analysed.

Results - The mean age of the patients was 40.6 years, the mean disease duration was 18.9 years, and the mean average muscle score (a numerical expression of limb weakness) was $5 \cdot 73$ out of 10 . Chest radiography showed unilateral paresis of the diaphragm in three patients. Increased residual volumes, with either increased or decreased total lung capacity, correlated inversely with disease duration. Respiratory muscle weakness was common but mild. Expiratory muscle function was more impaired than inspiratory muscle function and correlated positively with expiratory reserve volume.
\end{abstract}

Conclusions - Respiratory muscle strength is commonly impaired in limb girdle muscle dystrophy. A dissociation of the limb and mild respiratory muscle involvement is observed; wheelchair restriction does not predict worsening of pulmonary function, and patient age, disease duration, or degree of limb weakness do not predict pulmonary morbidity. The diaphragm is not disproportionately affected by the dystrophic process compared with limb muscles.

(Thorax 1994;49:61-65)

The heterogeneous causes of the limb girdle muscular dystrophy phenotype ${ }^{1-4}$ necessitate strict genetic, clinical, electromyographic, and histopathological criteria for its accurate delineation. The disease is characterised by expression in both men and women. ${ }^{12}$ Onset is usually late in the first decade, but may be in the second or third decades and even in middle age. ${ }^{2}$ Primary involvement of either the shoulder girdle or pelvic girdle muscles may occur with spread from the upper to the lower limbs or vice versa. ${ }^{2}$ A variable rate of progression is associated with inability to walk within 20-30 years of onset. ${ }^{2}$

Pulmonary involvement is frequently observed in patients with limb girdle muscle dystrophy, ${ }^{56}$ mild dyspnoea on exertion, chronic cough, and recurrent respiratory tract infections having been reported. ${ }^{6}$ Decreased maximum breathing capacity and vital capacity associated with a decrease in inspiratory reserve volume have been ascribed to inadequate thoracic expansion from weakened diaphragmatic and thoracic muscles. ${ }^{56}$ Morning headache, hypersomnolence, fatigue, and altered mental function were reported in three patients with limb girdle muscle dystrophy with alveolar hypoventilation and was ascribed to early and severe involvement of the diaphragm. ${ }^{57}$

No study has been published investigating dysfunction of the respiratory system in a relatively large group of subjects with limb girdle muscle dystrophy. Reasons may include the low prevalence of this disorder ${ }^{8}$ and controversies surrounding disease definition and, therefore, case selection. ${ }^{1910}$ In this cross sectional study pulmonary function tests were undertaken in 20 selected patients with limb girdle dystrophy. The aim was to establish (1) the prevalence of pulmonary dysfunction; (2) the type of dysfunction; and (3) any correlation between patient age, disease duration or general muscle weakness and lung or respiratory muscle dysfunction.

\section{Methods}

PATIENTS

Twenty patients (13 women and seven men) were identified; 14 were ambulant and six were wheelchair bound. As controversies surround the definition of limb girdle muscular dystrophy, ${ }^{1910}$ the following criteria updated from a previous classification ${ }^{2}$ were used to select patients.

(1) Inheritance pattern: autosomal recessive in five families (more than one sibling affected in four families (eight patients), one consanguineous marriage (one patient)), and 11 sporadic cases.

(2) Phenotype expression: all patients were weak in a symmetrical limb girdle, proximal distribution without facial involvement or contractures. Distal limb muscles were minimally involved only in the severely affected patients.

Department of
Neurology
J-P Stübgen
Lung Unit
G J Ras
C M Schultz
Department of
Internal Medicine,
University of
Pretoria, PO Box 667,
Pretoria, Republic of
South Africa
Institute for
Biostatistics, Medical
Research Council
G Crowther
Reprint requests to
Professor G J Ras.
Received 25 January 1993
Returned to authors
14 April 1993
Revised version received
26 August 1993
Accepted for publication
22 September 1993


Table 1 Mean (SD) anthropometric features of patients with limb girdle muscular dystrophy and control subjects

\begin{tabular}{lcc}
\hline & Patients $(n=20)$ & Controls $(n=20)$ \\
\hline Male: female & $7: 13$ & $7: 13$ \\
Age (years) & $40 \cdot 5(12 \cdot 7)$ & $40 \cdot 6(13 \cdot 1)$ \\
Height (cm) & $169 \cdot 7(11 \cdot 3)$ & $169 \cdot 4(10 \cdot 4)$ \\
Weight $(\mathrm{kg})$ & $71 \cdot 6(15 \cdot 5)$ & $69 \cdot 0(14 \cdot 8)$ \\
\hline
\end{tabular}

(3) Electromyographic findings were compatible with a progressive chronic myopathy.

(4) Muscle histopathological findings included dystrophic lesions (non-specific, degenerative and regenerative myopathic changes with necrotic and whorled fibres). The absence of an inflammatory cell infiltrate, ragged red fibres, features of metabolic or congenital myopathies, or chronic neurogenic changes excluded other causes of the limb muscular syndromes.

In addition, the absence of dystrophin abnormalities (immune peroxidase precipitation technique) in four sporadically affected men excluded Duchenne and Becker muscular dystrophies. ${ }^{11}$

No patient had cardiovascular or pulmonary symptoms disproportionate to the degree of weakness or physical activity. Three patients smoked about 10 cigarettes daily for four, 10, and 10 years, respectively; none had clinical features of obstructive airway disease. In 17 patients full inspiration chest radiographs were obtained in the standing or sitting position. In two of three patients suspected unilateral diaphragm weakness was further evaluated fluoroscopically by a sniff manoeuvre on a screening machine (Toshiba DC $1050 \mathrm{~F}$ ).

APPARATUS AND METHODOLOGY

To assess muscle strength manually a modification of the UK Medical Research Council (MRC) scale was chosen. ${ }^{12}$ Quantification of global muscle strength was obtained by testing limb movements around the neck, shoulders, elbows, wrists, hips, knees, and ankles; 17
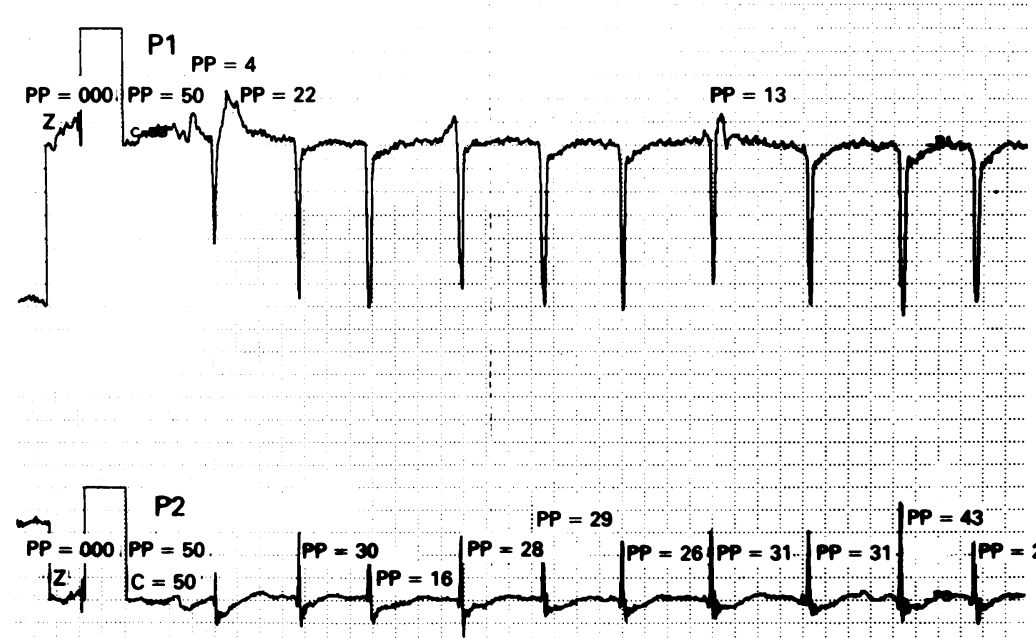

Figure 1 Tracings showing negative oesophageal (P1) and positive gastric (P2) pressure changes during a series of rapid sniff manoeuvres obtained by a microcapillary infusion method. muscles on both sides were evaluated. For purposes of analysis the MRC scale was converted to a 0-10 point system. The average muscle score is the numerical average of 34 muscles tested. Out of a possible maximum of 10 , the lower the number the weaker the patient. The mean muscle score for the patient group was 5.73 (range 1.94-8.65). A healthy age, sex, height and weight matched control group with normal spirometric values was chosen from non-smoking hospital personnel (table 1).

Lung function tests were performed on patients and 20 healthy controls after informed consent was obtained. Arterial blood from the radial artery was analysed before lung function testing on an ABL 300 blood gas apparatus (Radiometer, Copenhagen, Denmark). Spirometric testing, whole body plethysmography, and single breath carbon monoxide transfer measurements ${ }^{13}$ were performed using Medgraphics 1070 and 1085 systems respectively (Medgraphics, St Paul, Minnesota, USA). Each apparatus was calibrated before testing and all subjects were tested by the same operator.

Maximum inspiratory and expiratory pressures (MIP and MEP) were measured by the method of Black and Hyatt $^{14}$ using a plastic flanged mouthpiece (Bird No. 1560). All pressures were recorded as the highest pressure that could be generated after one second and which could also be sustained for one second or longer. MIP and MEP measurements were performed and the three best measurements recorded. Sufficiently long rest intervals were given before each measurement. Maximum voluntary ventilation (MVV) for 12 seconds was measured twice per patient after rest intervals. The measurement was repeated until $<5 \%$ repeatability was obtained.

The change in transdiaphragmatic pressure was measured during a maximal sniff manoeuvre (PDIS) and recorded on a microcapillary infusion system (JS Biomedicals, Ventura, California, USA). ${ }^{15}$ A triple lumen oesophageal catheter $75 \mathrm{~cm}$ long with an outer diameter of $2 \mathrm{~mm}$ was perfused with distilled water, connected to the pressure ports, and swallowed by the subject until the distal opening was in the stomach. The distance between the proximal and distal openings was $10 \mathrm{~cm}$. The pressure ports were then zeroed at functional residual capacity (FRC), suppressing internal pressures to atmospheric pressure; hence only the change in pressure from the FRC position during a maximal sniff manoeuvre with the mouth closed was determined. No local anaesthesia was necessary.

Frequency responses with this technique were rapid and no significant damping of peaks during a rapid inspiratory sniff manoeuvre was observed (fig 1). PDIs was calculated by subtracting the oesophageal pressure changes from the gastric pressure changes. At least 10 sniffs were performed after careful coaching and the mean of the three best results was used. Diaphragm muscle fatigue was prevented by a sufficiently long rest interval between each sniff. Peak inspiratory (PIF) and 
Table 2 Patient characteristics and results of lung function tests

\begin{tabular}{|c|c|c|c|c|c|c|c|c|c|}
\hline Sex & $\begin{array}{l}\text { Age } \\
(y)\end{array}$ & $\begin{array}{l}\text { Duration } \\
\text { of disease (y) }\end{array}$ & $A M S$ & $\begin{array}{l}F E V_{l} \\
(\%)\end{array}$ & $\begin{array}{l}F V C \\
(\%)\end{array}$ & $\begin{array}{l}F E V_{l} / F V C \\
(\%)^{*}\end{array}$ & $\begin{array}{l}T L C \\
(\%)\end{array}$ & $\begin{array}{l}R V \\
(\%)\end{array}$ & $\begin{array}{l}T_{L C O} / V_{A} \\
(\%)\end{array}$ \\
\hline$M$ & 66 & 6 & 8.65 & 84 & 83 & 78 & - & - & 83 \\
\hline $\mathrm{F}$ & 22 & 8 & $5 \cdot 20$ & 114 & 108 & 93 & 120 & 198 & 88 \\
\hline M & 27 & 10 & 5.09 & 93 & 98 & 77 & 125 & 161 & 95 \\
\hline $\mathrm{F}$ & 23 & 10 & 1.94 & 39 & 35 & 99 & 64 & 165 & - \\
\hline $\mathrm{F}$ & 41 & 11 & $7 \cdot 85$ & 107 & 99 & 87 & 114 & 120 & - \\
\hline $\mathrm{F}$ & 24 & 12 & $6 \cdot 71$ & 101 & 92 & 93 & 90 & 118 & 125 \\
\hline $\mathrm{F}$ & 34 & 13 & $8 \cdot 24$ & 100 & 99 & 82 & 121 & 199 & 111 \\
\hline $\mathrm{F}$ & 53 & 15 & 8.03 & 118 & 121 & 79 & 122 & 161 & 97 \\
\hline $\mathbf{F}$ & 33 & 15 & $4 \cdot 71$ & 130 & 111 & 97 & - & - & 85 \\
\hline $\mathrm{F}$ & 32 & 15 & 7.91 & 95 & 99 & 78 & 96 & 93 & 107 \\
\hline $\mathrm{F}$ & 50 & 17 & $8 \cdot 24$ & 123 & 109 & 88 & 122 & 128 & 80 \\
\hline$F$ & 35 & 18 & 6.90 & 100 & 89 & 92 & 106 & 134 & 110 \\
\hline M & 36 & 19 & 5.06 & 119 & 112 & 84 & 104 & 90 & 99 \\
\hline M & 46 & 22 & $8 \cdot 56$ & 90 & 87 & 80 & 91 & 113 & 90 \\
\hline M & 40 & 24 & $4 \cdot 29$ & 63 & 65 & 74 & 80 & 123 & - \\
\hline $\mathbf{M}$ & 43 & 29 & 4.97 & 116 & 109 & 84 & 107 & 118 & - \\
\hline$F$ & 46 & 30 & $2 \cdot 47$ & 109 & 96 & 89 & - & - & 95 \\
\hline $\mathbf{F}$ & 48 & 30 & 2.76 & 88 & 73 & 95 & - & - & 93 \\
\hline M & 45 & 31 & 3.88 & 100 & 92 & 84 & 106 & 113 & 89 \\
\hline $\mathrm{F}$ & 67 & 42 & $3 \cdot 12$ & 111 & 93 & 72 & - & - & - \\
\hline
\end{tabular}

AMS = average muscle score $\mathrm{FEV}_{1}=$ forced expiratory volume in one second $\mathrm{FVC}=$ forced vital capacity; $\mathrm{TLC}=$ total lung capacity; $\mathrm{RV}=\mathrm{r}$ esidual volume; $\mathrm{TLCO} / \mathrm{VA}_{\mathrm{A}}=$ transfer coefficient for carbon monoxide; $\%=$ percentage predicted of normal, $-=$ not done.

* Percentage absolute.

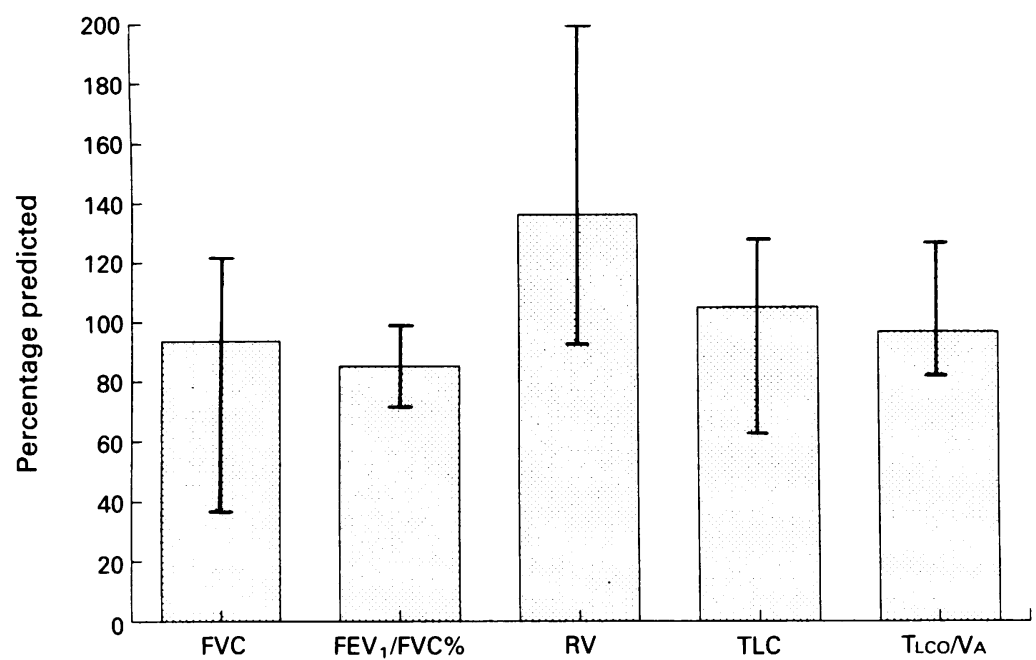

Figure 2 Lung function measurements in 20 patients with limb girdle muscular dystrophy. Results are presented as the percentage mean value plus the range of predicted values. $F V C=$ forced vital capacity; $F E V, / F V C=$ forced expiratory volume in one second as a percentage of FVC; RV = residual volume; TLC=total lung capacity; TLCO/VA= transfer coefficient for carbon monoxide.

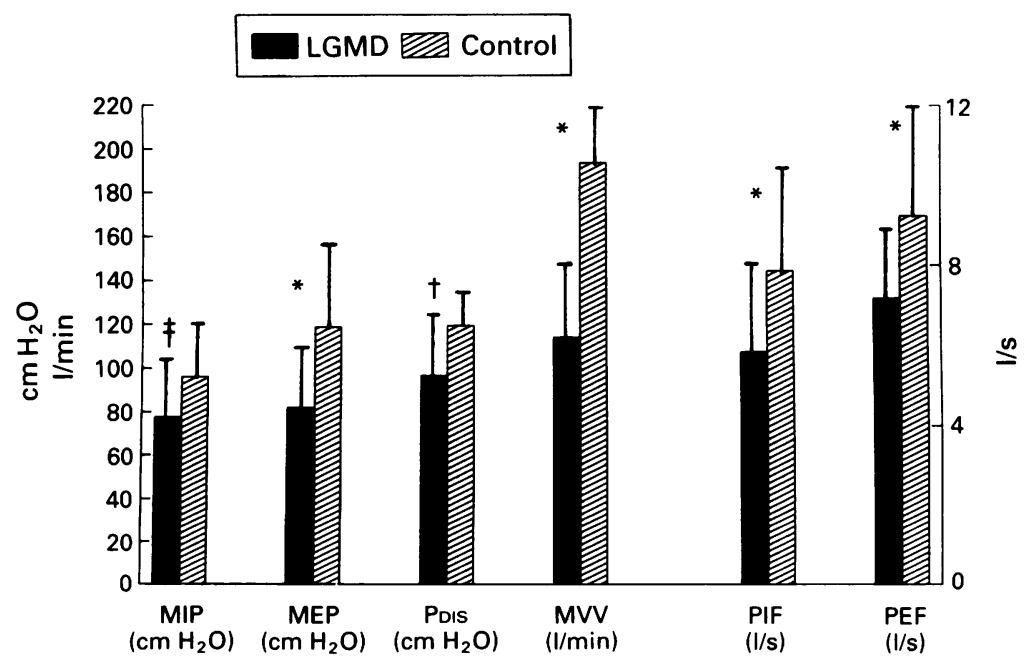

Figure 3 Respiratory muscle function in 20 patients with limb girdle muscular dystrophy (LGMD) and 20 healthy controls. Results are presented as the mean $(S D) . M I P=$ maximum inspiratory pressure; $M E P=$ maximum expiratory pressure; PDIS = transdiaphragmatic pressure change during an inspiratory sniff manoeuvre; $M V V=$ maximal voluntary ventilation; $P I F=$ peak inspiratory flow; $P E F=$ peak expiratory flow. ${ }^{*} p<0.001 ; \dagger p<0.01 ; \ddagger p<0.05$. expiratory flow (PEF) were determined as additional tests of global respiratory muscle function.

\section{STATISTICAL ANALYSIS}

Normal reference values for lung function tests were those of Schoenberg et $a l^{16}$ for dynamic spirometry, Morris et al ${ }^{17}$ for static spirometry, and Crapo and Morris ${ }^{18}$ for carbon monoxide transfer tests. The $\chi^{2}$ test was used to compare respiratory muscle function of patients with a control group. The Spearman correlation coefficient was applied to establish a correlation between the average muscle score, patient age, disease duration and lung or respiratory muscle function. The Mann-Whitney test was used to compare lung and respiratory muscle function of the ambulant subgroup with that of the wheelchair bound subgroup. The statistical significance of data was established at $\mathrm{p}<0.05$.

\section{Results}

The anthropometric data of patients and control subjects are shown in table 1 . Chest radiographs showed no skeletal or lung parenchymal abnormalities although elevated hemidiaphragms were present in three patients. Unilateral paresis of the diaphragm was subsequently confirmed fluoroscopically in one patient. An inverse correlation was found between disease duration and the average muscle score $(r=-0.48 ; \mathrm{p}=0.03)$, but not between age and the average muscle score $(p=0 \cdot 6)$.

The results of standard lung function tests are shown in table 2 and fig 2 . The total lung capacity (TLC) measured in 15 patients was reduced in two patients $(<80 \%$ of predicted values) and increased in five ( $>120 \%$ of predicted values). A reduced FVC (less than $80 \%$ of predicted values) associated with a normal $\mathrm{FEV}_{1} / \mathrm{FVC}$ ratio $(>0.8)$ was observed in three patients including the two patients with reduced TLC. Residual volumes (measured in 15 patients) were increased in nine patients ( $>120 \%$ of predicted values), possibly as a result of expiratory muscle weakness. The transfer coefficient and arterial blood gas analyses at rest were normal in all patients (blood gas data not given).

Respiratory muscle function results are shown in fig 3. No significant differences were found in parameters of lung and respiratory muscle function between the ambulant and wheelchair bound patient subgroups (data not shown). Significant impairment of global inspiratory and expiratory muscle function was found in patients compared with controls. The transdiaphragmatic sniff test, a more specific indicator of diaphragmatic muscle function, was also significantly abnormal in patients compared with the control group. Respiratory muscle weakness was mild in patients with limb girdle muscle dystrophy and the diaphragm was not disproportionately affected. Expiratory muscle strength was more impaired than inspiratory muscle strength and was 


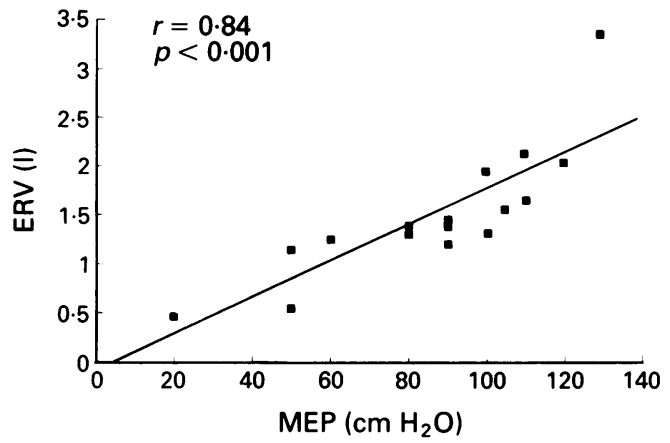

Figure 4 Correlation between expiratory reserve volume (ERV) and maximum expiratory pressure (MEP) in patients with limb girdle muscular dystrophy.

associated with an increased residual volume in most patients. A significant positive correlation was observed between the expiratory reserve volume and MEP ( $r=0.84 ; \mathrm{p}<0.001$; fig 4) and also between the average muscle score and MEP $(r=0.66 ; \mathrm{p}<0.002)$. Respiratory muscle endurance, assessed by measuring the maximum voluntary ventilation, was also significantly reduced $(p<0.001)$ in the patient group compared with the control group.

\section{Discussion}

The severity of pulmonary dysfunction and the disease stage at which this develops varies in different neuromuscular diseases. ${ }^{51920}$ In this study we investigated respiratory muscle function in 20 patients with limb girdle muscular dystrophy. The results were compared with an age and sex matched healthy control group. Comparing ambulant and wheelchair bound patients, a significant difference was only found in the degree of limb weakness. Patients were thus evaluated as a single group. Wheelchair restriction in itself did not predict worsening pulmonary function as in Duchenne dystrophy and spinal muscular atrophy. ${ }^{21}$ As the age of disease onset varied in this study there was, predictably, a poor correlation between patient age and the degree of limb weakness. However, as expected for a progressive illness an inverse correlation was observed between disease duration and limb weakness.

Respiratory muscle weakness was common in our patients but was mild. There was little or no relation to limb weakness and the diaphragm was not disproportionately affected. Early and severe involvement of the diaphragm, as previously reported in several case reports, ${ }^{57}$ was not observed in any of our patients. Neither clinical assessment nor chest radiography reliably indicated the presence or degree of respiratory muscle dysfunction in these physically inactive patients. Hypoventilation, hypoxaemia, or both, were not detected in any patient, implying a mild non-progressive respiratory disorder.

Expiratory muscle strength appeared more impaired than inspiratory muscle strength and this was associated with an increased residual volume and a decreased expiratory reserve volume in most patients. Changes in residual volume did not correlate with the degree of limb weakness. An unexplained increase in total lung capacity was observed in the absence of airflow limitation in five patients.

The mechanism of respiratory muscle weakness, particularly of the expiratory muscles which are predominantly abdominal, is unclear. Electromyographic and muscle biopsy findings in previously reported cases disclose significant heterogeneity with some cases showing mixtures of myopathic and neuropathic changes, and occasionally only neuropathic changes. ${ }^{122}$ It is not clear how homogeneous these cases were. No data are available on the histological features of the diaphragm and other respiratory muscles in limb girdle muscle dystrophy. Pathological changes in limb muscles are non-specific ${ }^{2224}$ and a similar non-specific myopathy of respiratory muscles is suspected.

No specific treatment is available for limb girdle muscle dystrophy. The value of passive stretching exercises to prevent contractures and deformities is unclear..$^{25}$ Active exercise against graded resistance may also be helpful in maximising residual muscle power and preserving function. ${ }^{2526}$ Periodic assessment of respiratory function may lead to the early recognition of pulmonary insufficiency. ${ }^{15}$ The data from this study, however, indicate only mild respiratory muscle impairment without progression to chronic respiratory failure.

1 Shields RW. Limb girdle syndromes. In: Engel AG, Banker BQ (eds). Basic and clinical myology. New York: McGraw-Hill, 1986:1349-65.

2 Walton JN, Nattrass FJ. On the classification, natural history and treatment of the myopathies. Brain 1954;77:12-231.

3 Munsat TL. The classification of human dystrophies. In: Rowland LP (ed). Pathogenesis of human muscular dystrophies. Amsterdam: Excerpta Medica, 1977:23-31.

4 Erb W. Ueber die juvenile Form der progressiven Muskelatrophie und ihre Beziehungen zur sogenannten Pseudohypertrophie der Muskeln. Dtsch Archiv Klin Med $1884 ; 34: 467-519$.

5 Newsom-Davis J. The respiratory system in muscular dystrophy. Br Med Bull 1980;36:135-8.

6 Kilburn KH, Eagen JT, Sieker HO, Heyman A. Cardiopulmonary insufficiency in myotonic and progressive muscumonary insufficiency in myotonic and progressive

7 Neustadt JE, Levy RC, Spiegel IJ. Carbon dioxide narcosis in association with muscular dystrophy. $\mathfrak{f} A M A$ 1964;187:616-7

8 Yates JRW, Emery AEH. A population study of adult onse limb girdle muscular dystrophy. $\mathcal{F}$ Med Genet 1985 22:250-7.

9 Panegyres PK, Mastaglia FL, Kakulas BA. Limb girdle syndromes. Clinical, morphological and electrophysiological studies. 7 Neurol Sci 1990;95:201-18.

10 Fowler WM, Nayak NN. Slowly progressive proximal weakness: limb-girdle syndromes. Arch Phys Med Rehabil 1983;64:527-38

11 Uchino $M$, Araki S, Miike T, Termoto H, Nakamura T, Yasutake $\mathrm{T}$. Localization and characterization of dystrophin in muscle biopsy specimens from Duchenne muscular dystrophy and various neuromuscula disorders. Muscle Nerve 1989;12:1009-16.

12 Mendell JR, Florence J. Manual muscle testing. Muscle Nerve 1990;13(Suppl): 16-20.

13 Ogilvie CM, Forster RE, Blakemore WS. A standard breathholding technique for the clinical measurement of the diffusion capacity of the lung for carbon monoxide. $f$ Clin Invest 1957;36:1-7.

14 Black LF, Hyatt RE. Maximal respiratory pressures: normal values and relationship to age and sex. Am Rev Respir Dis 1969;99:696-702.

15 Wanke T, Formanek D, Auinger M, Popp W, Zwick H, Irsigler $\mathrm{K}$. Inspiratory muscle performance and pulmonary function changes in insulin-dependent diabetes mellitus. Am Rev Respir Dis 1991;143:97-100.

16 Schoenberg JB, Beck GJ, Bonthuys A. Growth and decay of pulmonary function in healthy blacks and whites. Respir Physiol 1978;33:367-93.

17 Morris JF, Koski A, Johnson LC. Spirometric standard for healthy nonsmoking adults. Am Rev Respir Dis 1971;103:57-67.

18 Crapo RO, Morris AH. Standardized single breath normal 
values for carbon monoxide diffusion capacity. Am Rev values for carbon monoxide
Respir Dis 1981;123:185-9.

19 Kelly BJ, Luce JM. The diagnosis and management of neuromuscular diseases causing respiratory failure. Chest 1991;99:1485-94.

20 Serisier DE, Mastalgia FL, Gibson GJ. Respiratory muscle function and ventilatory control. I In patients with motor neuron disease. II In patients with myotonic dystrophy. $Q \mathcal{F}$ Med 1982;51:205-26.

21 Inkley SR, Oldenburg FC, Vignos PJ. Pulmonary function in Duchenne muscular dystrophy related to stage of disease. Am 7 Med 1974;56:197-306.

22 Bradley WG. The limb girdle syndromes. In: Vinken PJ,
Bruyn GW (eds). Handbook of clinical neurology. Vol 40. Amsterdam: North-Holland, 1979:433-69.

23 Pearson CM. Pathology of human muscular dystrophy. In: Bourne GH, Golarz MN (eds). Muscular dystrophy in man and animals. New York: Hafner, 1963:1-27.

24 Astrom KE, Adams RD. The pathological reactions of the skeletal muscle fibre. In: Vinken PJ, Bruyn GW (eds). Handbook of clinical neurology. Vol 40. Amsterdam: North-Holland, 1979:197-274.

25 Siegel IM. The management of muscular dystrophy: a clinical review. Muscle Nerve 1978;1:453-60.

26 Baydur A. Respiratory muscle function in systemic disorders. Semin Respir Med 1988;223-38.

\section{Adventitia}

\section{Asbestos on my desk}

A chunk of asbestos ore used to sit on my desk. It came from the Lac d'Amiante Asbestos Company, Quebec, which I visited after an international symposium on asbestos in Montreal in 1982. The mining explosions we watched were, however, less dramatic than the heated discussions on whether any asbestos could be used safely. My subsequent editorial reminds me that I had naively hoped to hear new evidence on whether thresholds for carcinogenicity exist. But no new data on this central issue were reported, and the main interest lay in confrontations between scientists, government representatives, trade unionists, and industrialists.

I was invited to Montreal because of two review articles on asbestos in a series on pollution I wrote for the $B M \mathcal{F}$. My work there included writing articles and acting as correspondence editor. The latter also yielded fascinating controversies. Most memorable was the correspondence on the first large study, by Hirayama, linking passive smoking and lung cancer. Months after publication of the paper in 1981 I was mystified to receive letters about it that were addressed to me personally. They turned out to be part of a campaign run by the US Tobacco Institute and we felt obliged to reopen the correspondence, which finished with a reply by Hirayama. But it was difficult to be sure where the truth lay and I am happy to see that his conclusion has been confirmed by later studies - and that environmental tobacco smoke has been accepted as a carcinogen by various public bodies, including Britain's Independent Scientific Committee on Smoking and Health and the US Environmental Protection Agency.

The asbestos on my desk was the most tangible but by no means the only legacy of the subjects on which I have written for the $B M F$, and I am lucky to have had such wonderful opportunities and the help of so many interesting people. The first two series (anonymous) were on road accidents and accident and emergency services. The former has been particularly fruitful in enabling me to be a member of the Parliamentary Advisory Council on
Transport Safety - an organisation that actually gets things done - and to write further articles; in $1987 \mathrm{I}$ also did a report on accidents in general for a colloquium of the Royal Colleges. And happily my behaviour as a driver and a pedestrian has been lastingly influenced.

Then came the pollution series, which also included articles on noise (for which I carried a noise meter everywhere for a fortnight), ionising radiation, lead, air pollution, etc. Repeatedly I learnt the depressing lesson that proponents of the radical view, which I would start by sympathising with, were often not reliable in their handling of evidence. The principle of not exploiting or being careless with people is surely robust enough, and in any case the certainties generally provided plenty of ammunition.

I did the last series, on rehabilitation, while technical editor of Thorax, and I could not have combined the two without the support and encouragement of my husband. I visited many centres that did wonderful work for people with strokes and head injuries, heart problems, and mental illness, among others, and occasionally attended discussions and case conferences, or lay on the floor doing exercises or even helped - this most poignantly in an "exercise" group in a geriatric long stay ward, where the only woman who seemed to know what was going on begged me to visit them again. This series has since led me to many conferences and the chance to report on them.

Subjects I have visited more briefly include exercise and health, the arts in illness and disability, and terminal care. After a conference on this last in 1980 I wrote an editorial, "Give sorrow words," that was one of the most useful things I have done because a consultant told me that he used my concluding quotation on a ward round with his students. The words, which had been quoted at the conference, are from The House at Pooh Corner: "Said Eeyore ... 'I make it 17 days come Friday since anybody spoke to me.' . . . Said Rabbit ... 'I was here myself a week ago.' 'Not conversing,' said Eeyore. 'Not first one and then the other. You said "Hallo" and flashed past.", DAPHNE GLOAG 